\title{
Modification of (DGEBA) epoxy resin with maleated depolymerised natural rubber
}

\author{
K. Dinesh Kumar ${ }^{1,2}$, B. Kothandaraman ${ }^{1 *}$ \\ ${ }^{1}$ Department of Rubber and Plastics Technology, MIT campus, Anna University, Chennai-6000 44, India \\ ${ }^{2}$ Current address: Rubber Technology Centre, Indian Institute of Technology, Kharagpur-721302, India
}

Received 30 December 2007; accepted in revised form 13 March 2008

\begin{abstract}
In this work, diglycidyl ether of bisphenol A (DEGBA) type epoxy resin has been modified with maleated depolymerised natural rubber (MDPR). MDPR was prepared by grafting maleic anhydride onto depolymerised natural rubber. MDPR has been characterized by Fourier transform infrared (FT-IR) spectroscopy and nuclear magnetic resonance spectroscopy. MDPR was blended with epoxy resin at three different ratios (97/3, 98/2 and 99/1), by keeping the epoxy resin component as the major phase and maleated depolymerised natural rubber component as the minor phase. The reaction between the two blend components took place between the acid/anhydride group in the MDPR and the epoxide group of the epoxy resin. The proposed reaction schemes were supported by the FT-IR spectrum of the uncured Epoxy/MDPR blends. The neat epoxy resin and Epoxy/MDPR blends were cured by methylene dianiline (DDM) at $100^{\circ} \mathrm{C}$ for three hours. Thermal, morphological and mechanical properties of the neat epoxy and the blends were investigated. Free volume studies of the cured, neat epoxy and Epoxy/MDPR blends were correlated with the morphological and mechanical properties of the same systems using Positron Annihilation Lifetime Studies.
\end{abstract}

Keywords: thermosetting resins, epoxy resin, maleated depolymerised natural rubber, blending, positron annihilation lifetime studies

\section{Introduction}

Epoxy resins are very important class of thermosetting polymers that often exhibit high tensile strength and modulus, excellent chemical and corrosion resistance and good dimensional stability. Hence they are widely used in structural adhesives, surface coatings, engineering composites, electrical laminates etc. [1]. The major drawback of epoxy resins in the cured state is that they are extremely brittle materials having fracture energies two orders of magnitude lower than engineering thermoplastics and three orders lower than metal [1-3]. As the result they have limited utility in applications requiring high impact and fracture strengths. This inherent brittleness causes poor peeling and shear strength of epoxy based adhesives [3]. Hence toughening of epoxy resin has been the subject of intense investigation throughout the world. Epoxy resins are most successfully toughened by dispersing rubber particles as a distinct phase of microscopic particles in the epoxy matrix [4].

This can be achieved by two ways: 1) by blending with low molecular weight functionalized liquid rubbers, having restricted solubility and limited compatibility with epoxy hardener mixture and undergo phase separation at a certain stage of curing reaction leading to a two phase microstructure, 2) by directly dispersing preformed rubbery particles in the epoxy matrix. Rubber toughened epoxies was first reported by McGarry and Willner in 1968, using low molecular weight carboxyl terminated copolymer of butadiene and acrylonitrile (CTBN, 
Goodrich) [5]. They modified different grades of diglycidyl ether of bisphenol A (DGEBA) epoxies with CTBN and cured with piperidine to get a network having two-phase microstructure and reported a ten-fold increase in fracture toughness. Approximately $5-20 \%$ of low molecular weight reactive liquid rubbers like CTBN dispersed in the hot epoxy resin can lead to a multiphase toughened epoxy system on curing $[5,6]$. To optimize toughening, parameters such as modifier structure, molecular weight, solubility and rubber concentration must be clearly defined. These parameters are responsible for the dynamics of multiphase morphology $[5,6]$. Following this pivotal work extensive research has been done for the past two and a half decades to understand the principle of morphology development, morphology and fracture property relationship and the mechanism of toughening [7-10]. Nowadays various functionalized synthetic liquid rubbers have been synthesized and investigated as a replacement of CTBN rubber [10-14].

However, till today, a liquid modifier for epoxy resin which is easily available and easy to modify has not been explored. Therefore, in this work, epoxy resin has been modified with depolymerised natural rubber (DPR), a rubber which is very easily available. Depolymerised natural rubber (DPR) has been functionalized by grafting maleic anhydride on it by a simple thermal reaction between the depolymerised natural rubber (DPR) and maleic anhydride. In this paper the role of maleated depolymerised natural rubber (MDPR) as a modifier for the liquid epoxy resin has been studied with reference to the mechanical, thermal, and morphological properties of the cured neat epoxy and Epoxy/MDPR blends. Furthermore, the effect of modifier on the mechanical and morphological properties and their correlation with the free volume data have been analyzed using positron annihilation lifetime spectroscopy (PALS).

Positron annihilation lifetime spectroscopy (PALS) is a sophisticated tool used for determining the nanometer sized free volume holes and their relative number densities (i.e. concentration) in polymers $[15,16]$. Till today, only few reports are available regarding the free volume studies of the rubber modified epoxies through PALS technique [17-18]. Especially PALS studies of epoxy-depolymerised natural blends are not available. Therefore, in this paper, PALS has been used as a complemen- tary tool to understand the relationship between the free volume and the mechanical properties of the cured neat epoxy and Epoxy/MDPR blend.

\section{Materials and methods}

\subsection{Materials}

Depolymerised natural rubber (DPR) with number average molecular weight $\left(M_{n}\right)$ around $36000 \mathrm{~g} / \mathrm{mol}$ was obtained from Carborundum universal India private limited, Chennai, India. (DGEBA) liquid epoxy resin with the epoxy equivalent of $170 \mathrm{~g}$ was used as received form Ciba-Geigy India private limited, Mumbai, India. Methylene dianiline (DDM) (HT 972) curing agent was used as received from Ciba-Geigy India private limited, Mumbai, India. Maleic anhydride (Laboratory Reagent) and Triphenylphosphine (Laboratory Reagent) were used as received from Hipure chemicals India private limited, Chennai, India.

\subsection{Synthesis of maleated depolymerised natural rubber (MDPR)}

$20 \mathrm{~g}$ of depolymerised natural rubber (DPR) was placed in a $100 \mathrm{ml}$ two necked glass beaker fitted with a stirrer, thermometer and a gas inlet. After the system was well purged with an inert gas the temperature was brought to be in the range of 200$230^{\circ} \mathrm{C}$. The system was allowed to remain in the same temperature for 10 minutes. Then $2 \mathrm{phr}$ (parts per hundred on depolymerised natural rubber) of maleic anhydride was added to the system and nitrogen was bubbled slowly to remove dissolved oxygen. The mixture was heated and stirred at the temperature between $200-230^{\circ} \mathrm{C}$ for 20 minutes. Then the mixture is allowed to cool to room temperature. Then maleated depolymerised natural rubber (MDPR) was removed from the beaker.

\subsection{Percentage grafting of maleic anhydride}

The maleic anhydride grafted sample was taken in a filter paper and placed in the Sohxlet apparatus for extraction. Each extraction was carried out for $24 \mathrm{~h}$, using acetone as the extracting medium for complete removal of unreacted maleic anhydride. The grafted polymer (MDPR) is fully insoluble in acetone. After the extraction, the samples within filter paper were dried under vacuum for $72 \mathrm{~h}$ at $70^{\circ} \mathrm{C}$ till 
they showed no weight variation $\left(W_{g}\right)$. The extent of grafting was calculated from the weight gain by the samples using the Equation (1):

$[\%]$ Grafting $=\frac{W_{g}-W_{0}}{W_{0}} \cdot 100$

where, $W_{g}$ - weight of grafted DPR and $W_{0}-$ weight of DPR before grafting.

\subsection{Epoxy-MDPR network formation}

The epoxy resin and maleated depolymerised natural rubber (MDPR) mixtures were blended with each other in the ratio $97 / 3,98 / 2,99 / 1$, by keeping the epoxy resin component as the major phase and maleated depolymerised natural rubber component as the minor phase. The epoxy resin and maleated depolymerised natural rubber mixtures were heated in a beaker at $120^{\circ} \mathrm{C}$ (with $1 \%$ triphenylphosphine catalyst) for 1 hour. The Epoxy/MDPR mixtures were allowed to reach room temperature. $27 \mathrm{phr}$ of methylene dianiline (curing agent) was slowly dissolved in neat epoxy and in each 99/1, 98/2, 97/3 (Epoxy/MDPR) mixtures at $80^{\circ} \mathrm{C}$, under vacuum to remove entrapped air bubbles. Then they were mixed and poured in aluminum molds, and allowed to cure at $100^{\circ} \mathrm{C}$ for 3 hours. The samples neat epoxy, 99/1, 98/2, 97/3 (Epoxy/MDPR) blends were designated as E0, E1, E2 and E3 respectively.

\subsection{Fourier transform infrared spectroscopy (FT-IR)}

The infrared spectroscopy of the maleated depolymerised natural rubber and Epoxy/MDPR (uncured state) blends were recorded in with a Perkin-Elmer FT-IR spectrophotometer. The FT-IR spectra of the samples (liquid state) were taken at room temperature $\left(25^{\circ} \mathrm{C}\right)$ using an optical cell. The samples were scanned from 4000 to $400 \mathrm{~cm}^{-1}$ with a resolution of $4 \mathrm{~cm}^{-1}$. All spectra were reported after an average of 32 scans.

\subsection{Nuclear magnetic resonance spectroscopy (NMR)}

The ${ }^{1} \mathrm{H}$-NMR spectroscopy of the maleated depolymerised natural rubber was recorded with Bruker AC-200 spectrometer (Switzerland) at $200 \mathrm{MHz}$ with $\mathrm{CDCl}_{3}$ as solvent.

\subsection{Measurement of glass transition temperature $\left(T_{g}\right)$ by differential scanning calorimetry (DSC)}

The $T_{g}$ of the cured neat epoxy and Epoxy/MDPR blends was measured by differential scanning calorimetry (DSC), NETZSCH DSC 204 in the temperature range of 30 to $200^{\circ} \mathrm{C}$ at a heating rate of $10^{\circ} \mathrm{C}$ per minute. The samples of $5-10 \mathrm{mg}$ were encapsulated in standard aluminum pans.

\subsection{Mechanical properties}

\subsubsection{Tensile stress-strain properties of neat epoxy and Epoxy/MDPR blends}

The tensile tests were carried according to ASTM D 638. The tensile specimens with dimension of $60 \mathrm{~mm} \times 10 \mathrm{~mm}$ with thickness of $2 \mathrm{~mm}$ were prepared by casting. The tensile strength, tensile modulus and elongation at break values of the neat epoxy and Epoxy/MDPR blends were identified. The tensile tests were carried at a cross head speed of $1 \mathrm{~mm} / \mathrm{min}$. Five test samples from each formulation were tested and the average values were reported.

\subsubsection{Flexural stress-strain properties of neat epoxy and Epoxy/MDPR blends}

The flexural tests were carried according to ASTM D 790. The flexural specimens with dimension of $80 \mathrm{~mm} \times 25 \mathrm{~mm}$ with thickness of $2 \mathrm{~mm}$ were prepared by casting. The flexural strength, flexural modulus and flexural strain to failure values of the neat epoxy and Epoxy/MDPR blends were identified. The flexural tests were carried at a cross head speed of $3 \mathrm{~mm} / \mathrm{min}$. Five test samples from each formulation were tested and the average values were reported.

\subsubsection{Izod unnotched impact test of neat epoxy and Epoxy/MDPR blends}

The Izod unnotched impact test was carried out according to ASTM D 4812-93 specifications using an impact tester with a striking velocity of $3.35 \mathrm{~m} \cdot \mathrm{s}^{-1}$. Impact test specimens in all the cases were prepared by casting in to rectangular shaped cavities $\left(125 \times 10 \times 10 \mathrm{~mm}^{3}\right)$. Tests are run on a TMT N 431 impact tester type machine equipped 
with a hammer. Five test samples from each formulation were broken. Average impact strength (IS) values were reported. The impact test was carried out at $25^{\circ} \mathrm{C}$ and the impact energy was reported in $\mathrm{J} \cdot \mathrm{m}^{-2}$. The Izod IS is calculated by Equation (2):

$$
\mathrm{IS}=\frac{U_{1}-U 2}{w \cdot t} \quad\left[\mathrm{~J} / \mathrm{m}^{2}\right]
$$

where $U_{1}$ is the impact energy [J], $U_{2}$ the residual energy $[\mathrm{J}], w$, the specimen width $[\mathrm{m}]$, and $t$, the specimen thickness $[\mathrm{m}]$.

\subsection{Morphological study}

\section{Scanning electron microscopy (SEM) studies}

Morphological analysis of the tensile fractured neat epoxy and Epoxy/MDPR blends were studied using JEOL (JSM-5800) Scanning electron microscopy after sputter coating the fractured sample surface with gold.

\subsection{Positron annihilation lifetime measurements}

Positron annihilation lifetime spectra were recorded for the cured neat epoxy and Epoxy/MDPR blends using positron lifetime spectrometer. The spectrometer consists of a fast-fast coincidence system with $\mathrm{BaF}_{2}$ scintillators coupled to photomultiplier tubes type XP2020/Q with quartz window as detectors. The $\mathrm{BaF}_{2}$ scintillators were conical shaped to achieve better time resolution. The two identical pieces of the sample were placed on either side of a $17 \mu \mathrm{Ci}{ }^{22} \mathrm{Na}$ (a 17 micro Curie Na-22) positron source, deposited on a pure Kapton foil of $0.0127 \mathrm{~mm}$ thickness. This sample-source sandwich was placed between the two detectors of the spectrometer to acquire lifetime spectrum. The ${ }^{60} \mathrm{Co}$ source was used to acquire the prompt time spectrum, which gave $180 \mathrm{ps}$ as the resolution of the spectrometer. However, to reduce the acquisition time and increase the count rate, the spectrometer was operated at 220 ps. All lifetime measurements were performed at room temperature with more than a million counts under each spectrum recorded in a time of 1 to $2 \mathrm{~h}$. Source correction term and resolution functions were estimated from the lifetime of well-annealed aluminum using the program RESOLUTION [17]. Since single Gaussian resolution function did not yield convergence, the resolution function was resolved further into three Gaussian components, which produced quick and good convergence. The net resolution function, however, for this remained at $220 \mathrm{ps}$. The compliancy of the resolution function was tested with well characterized polymer samples like PC and PTFE and the results obtained agreed very well with literature reported values. Therefore, three Gaussian resolution functions were used in the present analysis of positron lifetime spectra in all the blends and pure polymer samples. All spectra were analyzed into three lifetime components with the help of the computer program PATFIT-88 [17] with proper source and background corrections. The values of the free volume hole size, $V_{f}$ in $\mathrm{nm}^{3}$; the number density of the free volume holes $I_{3}$, in percentage and the fractional free volume $F_{v}$; the product of $V_{f}$ and $I_{3}$ was determined from the PALS measurements.

\section{Results and discussion}

\subsection{Characterization of maleated depolymerised natural rubber (MDPR)}

\subsubsection{Structural characterization of MDPR by FT-IR spectroscopy}

The FT-IR spectra of depolymerised natural rubber (DPR) and maleated depolymerised natural rubber

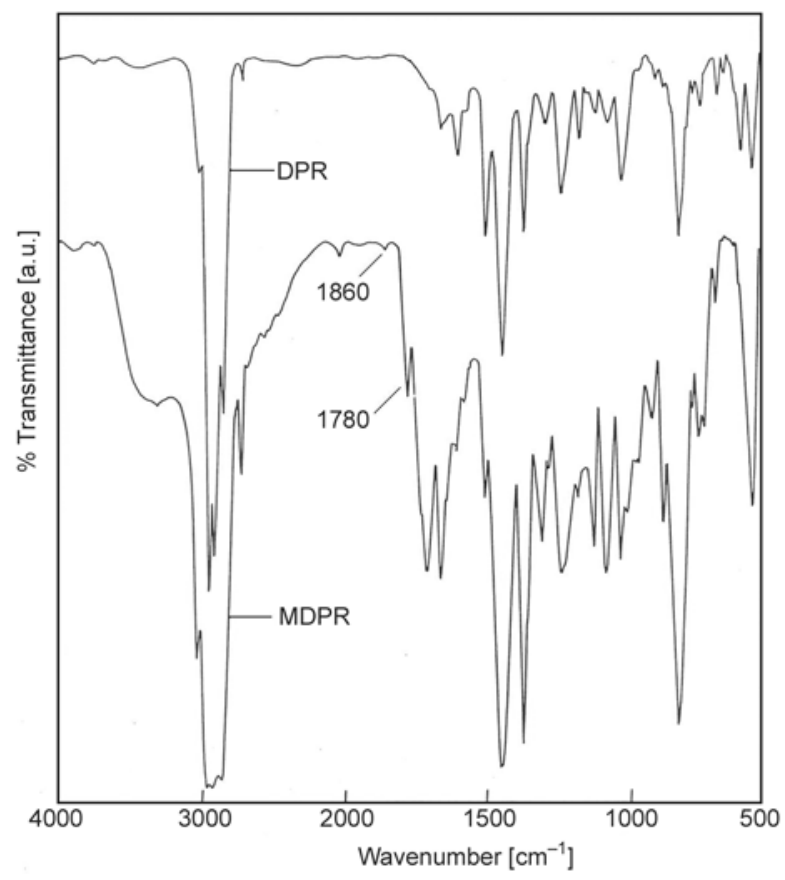

Figure 1. FT-IR Spectra of depolymerised natural rubber (DPR) and maleated depolymerised natural rubber (MDPR) 


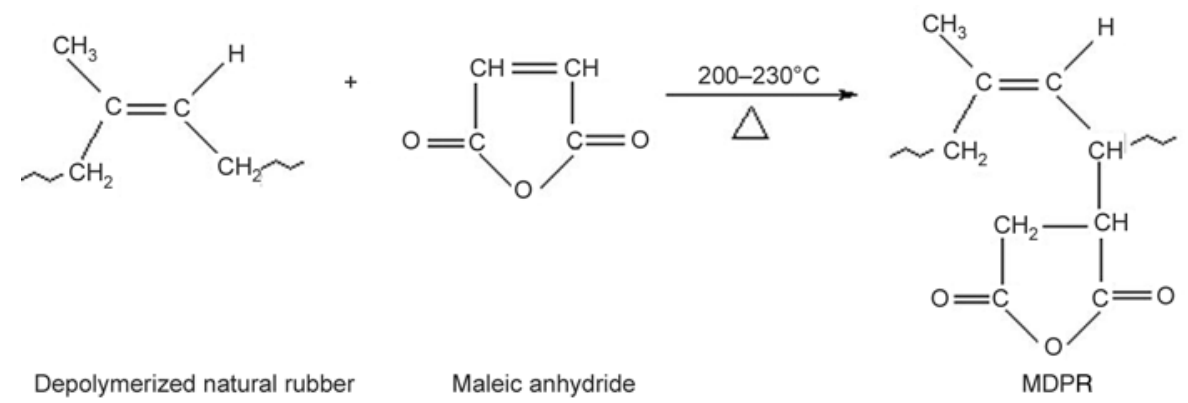

Figure 2. Grafting of maleic anhydride on depolymerised natural rubber (DPR) through Diels-Alder reaction mechanism

(MDPR) are shown in Figure 1. DPR shows the following characteristic peaks at 1640,885 , and $1370 \mathrm{~cm}^{-1}$, for $-\mathrm{C}=\mathrm{C}-$ stretching, $=\mathrm{C}=\mathrm{CH}_{2}$ (Vinylidene) stretching, and $-\mathrm{CH}_{2}$ stretching. In the FT-IR spectra of MDPR, the succinic anhydride function has been readily identified by the two absorption bands at 1780 and $1860 \mathrm{~cm}^{-1}$, which suggests the grafting of maleic anhydride on DPR through Diels-Alder mechanism [19]. Derouet et al., modified liquid natural rubber by maleic anhydride through similar type of reaction mechanism [19]. Additionally, another band was identified in the region around $1700 \mathrm{~cm}^{-1}$ which characterizes the succinic anhydride ring opening with the formation of carboxylic acid function due the presence of non rubber constituents in the DPR [19]. These characteristic peaks of succinic anhydride and carboxylic acid functions of MDPR were found along with the other characteristic peaks of depolymerised natural rubber. This shows that on reaction of depolymerised natural and maleic anhydride there is no loss in unsaturation or change in the cis-/trans-ratio of depolymerised natural rubber. This finding is in line with the results reported by Nauton [20]. From Equation (1), the percentage grafting of maleic anhydride has been calculated to be around $1.8 \%$. The plausible reaction between depolymerised natural rubber and maleic anhydride through DielsAlder mechanism is given in Figure 2.

\subsubsection{Structural characterization of MDPR by 1H-NMR spectroscopy}

In the ${ }^{1} \mathrm{H}-\mathrm{NMR}$ spectra of MDPR, fixation of maleic anhydride on DPR was characterized by a chemical shift at $\delta H=2.3-2.8 \mathrm{ppm}$, which characterizes the protons on the succinic ring and confirms the grafting of maleic anhydride on DPR, through Diels-Alder mechanism [19]. The ${ }^{1} \mathrm{H}-\mathrm{NMR}$ spectrum of MDPR was compared with the ${ }^{1} \mathrm{H}-\mathrm{NMR}$ spectrum of depolymerised natural rubber available in literature [21]. The assignment of various ${ }^{1} \mathrm{H}-\mathrm{NMR}$ peaks of depolymerised natural rubber are, $8.0 \tau$-which characterizes the methylene protons $\left[-\underline{\mathrm{CH}}_{2}-\mathrm{C}\left(\mathrm{CH}_{3}\right)=\mathrm{CH}-\underline{\mathrm{CH}}_{2}-\right]$ on NR and $8.33 \tau$-which characterizes the cis double bond methyl protons $\left[-\mathrm{C}\left(\underline{\mathrm{CH}}_{3}\right)=\mathrm{CH}-\right]$ on NR [22].

\subsection{Characterization of reactions between epoxy resin and MDPR}

\subsubsection{FT-IR spectrum of uncured Epoxy/MDPR blends}

The FT-IR spectra of the neat epoxy (E0) and Epoxy/MDPR blend (E3) are shown in Figure 3. While blending MDPR with liquid epoxy resin, the secondary alcohol groups present in the epoxy resin $\left(1297 \mathrm{~cm}^{-1}\right)$ can open the anhydride ring of MDPR leading to the formation of ester and carboxyl groups. This reaction is supported by the occurrence of a characteristic peak of saturated ester $(\mathrm{C}=\mathrm{O})$ at $1735 \mathrm{~cm}^{-1}$. The plausible reaction between

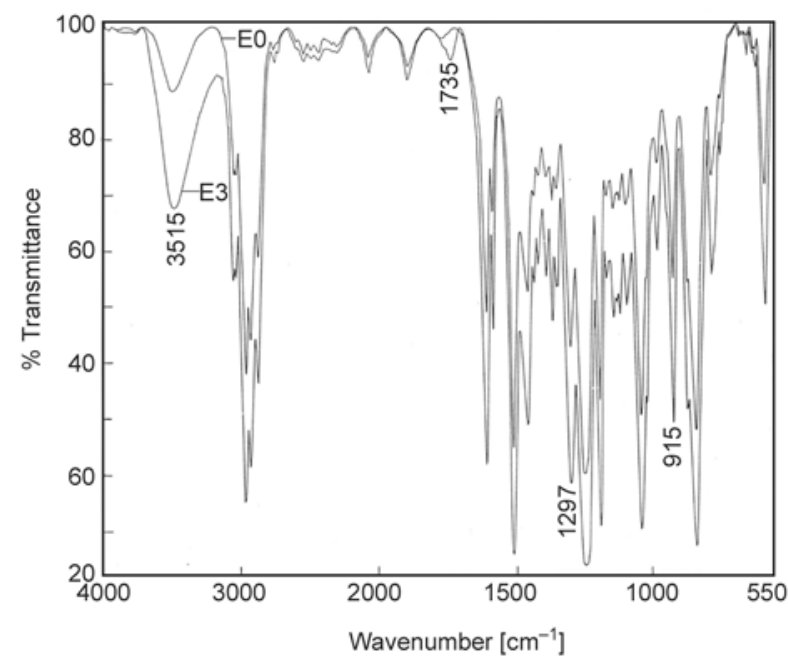

Figure 3. FT-IR Spectra of the uncured samples E0 and E3 


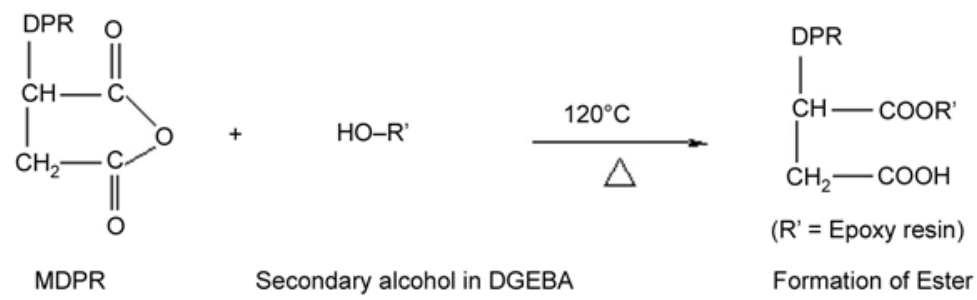

Figure 4. Reaction between maleated depolymerised natural rubber (MDPR) and secondary alcohol group of epoxy resin

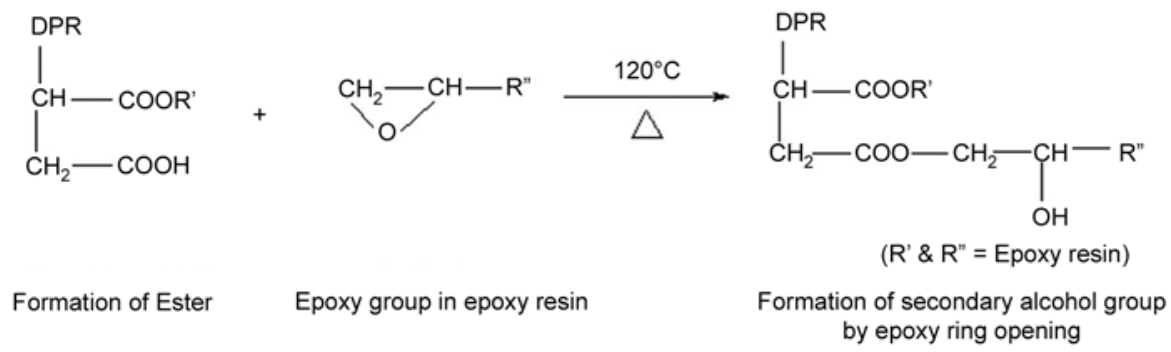

Figure 5. Reaction between the carboxyl group of maleated depolymerised natural rubber (MDPR) and the epoxy group of epoxy resin

MDPR and epoxy resin is shown in Figure 4. The carboxyl group formed will further react with the epoxide group of the epoxy resin leading to the formation of new secondary alcohol groups. This reaction is shown in Figure 5.

Another possible reaction is, some of the anhydride ring in the MDPR must have been opened and converted in to carboxyl groups by the impurities like non rubber constituents. Generally, in maleic anhydride grafted natural rubber, some of the anhydride rings has a tendency to break and get converted in to carboxyl groups. This type of reaction is believed to happen due to the impurities like non rubber constituents in the DPR [19]. While blending Epoxy/MDPR the carboxyl groups in the MDPR can react with the epoxide group of the epoxy resin, leading to the formation of new secondary alcohol groups. This reaction is shown in Figure 6.

By the above two possible mechanisms, maleated depolymerised natural rubber (MDPR) can be attached to the epoxy backbone to some extent. The FT-IR spectra of the Epoxy/MDPR blend (E3) (Figure 3) elucidate the reaction between the MDPR and the epoxy resin. In the FT-IR spectra of the uncured Epoxy/MDPR blends, after the reaction of MDPR with epoxy resin, there is a decrease in the epoxide band intensity at $915 \mathrm{~cm}^{-1}$ with the concomitant increase in secondary alcohol band intensity and free alcohol band intensity at 1297 and $3500 \mathrm{~cm}^{-1}$ respectively when compared to the FT-IR spectra of the uncured neat epoxy resin. This confirms the reaction between the acid/anhydride groups of MDPR and the epoxide group of the epoxy resin which results in the formation of secondary alcohol groups. The reaction schemes between MDPR and epoxide group of epoxy resin has been established by calculating the areas of epoxide peak at $915 \mathrm{~cm}^{-1}$, secondary alcohol peak at $1297 \mathrm{~cm}^{-1}$ and aromatic group peak at $1500 \mathrm{~cm}^{-1}$ in the respective FT-IR spectra of the uncured neat epoxy (E0) and Epoxy/MDPR blend (E3). The<smiles>O=C(O)CC(C(=O)O)C(=O)O</smiles>

Formation of Ester

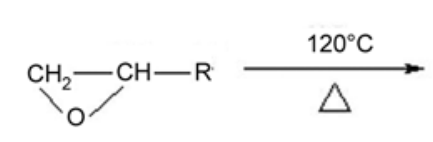

Epoxy group in epoxy resin

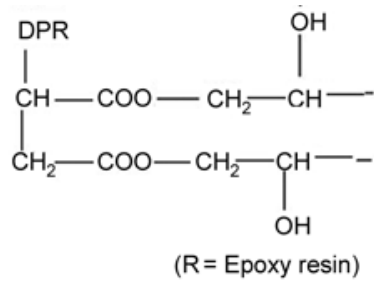

Formation of secondary alcohol group by epoxy ring opening

Figure 6. Reaction between the carboxyl groups of maleated depolymerised natural rubber (MDPR) and the epoxy group of epoxy resin 
ratios of epoxide peak area to aromatic peak area, secondary alcohol peak area to aromatic peak area were calculated from the respective FT-IR spectrums. From these ratio values the reaction schemes between MDPR and Epoxy resin has been predicted.

\subsection{Thermal analysis}

Figure 7 shows the DSC traces of neat epoxy resin and Epoxy/MDPR blends. The glass transition temperature $\left(T_{g}\right)$ values of cured neat epoxy and Epoxy/MDPR blends are included in Table 1. Addition of MDPR to epoxy resin does not produce

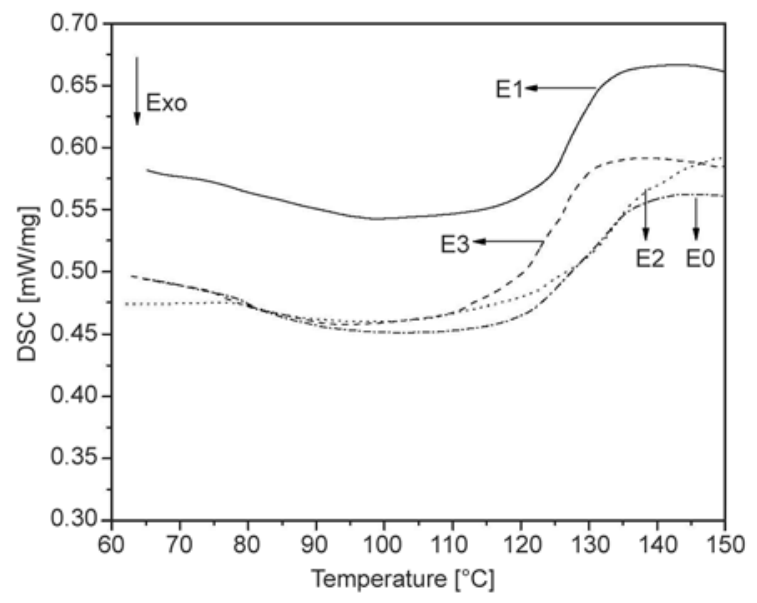

Figure 7. DSC traces of cured samples E0, E1, E2 and E3 and significant change in the $T_{g}$ value of the neat epoxy resin. This can be attributed to the limited compatibility between the blend components. Generally, in the case of more miscible epoxy-liquid rubber systems, the glass transition region will be broader [4, 23]. Here, the glass transition region is very narrow indicating a very limited compatibility between the blend components and also clearly suggest a possibility of distinct phase separation. In this case, the hardener was mixed with liquid epoxy resin at $80^{\circ} \mathrm{C}$ and the mould was kept in the oven at $100^{\circ} \mathrm{C}$. This would have given more time for gelation. However, at a higher temperature the viscosity will be much less and the reaction between epoxy and the hardener would be faster, and phase separations of the smaller particles will be more efficient. It must be remembered that as the epoxy starts curing, the rubber will precipitate faster thus, more efficient phase separation but with smaller precipitated rubber particles can be obtained. This prediction is confirmed and explained in detail in the later section on the morphological studies of the Epoxy/MDPR blends.

\subsection{Mechanical properties}

The tensile strength, tensile modulus, elongation at break [\%]; flexural strength, flexural modulus and

Table 1. Glass transition temperature $\left(T_{g}\right)$ and free volume parameters for the neat and the modified epoxies

\begin{tabular}{|l|c|c|c|c|}
\hline \multicolumn{1}{|c|}{ Modifier (PHR) } & $\begin{array}{c}\text { Free volume hole size } \\
\mathbf{V}_{\mathbf{f}}\left[\mathbf{n m}^{3}\right]\end{array}$ & $\begin{array}{c}\mathbf{0 - P s} \text { intensity } \\
\mathbf{I}_{\mathbf{3}}[\mathbf{\%}]\end{array}$ & $\mathbf{F}_{\mathbf{V R}(\%)}=\mathbf{V}_{\mathbf{f}} \mathbf{\mathbf { I } _ { \mathbf { 3 } }}$ & $\mathbf{T}_{\mathbf{g}}\left[{ }^{\circ} \mathbf{C}\right]$ \\
\hline Nil (E0) & 5.92 & 24.1 & 1.427 & 125 \\
\hline MDPR(1) (E1) & 6.01 & 24.0 & 1.442 & 122 \\
\hline MDPR(2) (E2) & 6.22 & 23.8 & 1.480 & 128 \\
\hline MDPR(3) (E3) & 5.92 & 24.8 & 1.468 & 120 \\
\hline
\end{tabular}

Table 2. Tensile, flexural and impact properties of the samples E0, E1, E2 and E3

\begin{tabular}{|c|c|c|c|c|}
\hline \multirow{5}{*}{$\begin{array}{l}\text { Tensile } \\
\text { properties }\end{array}$} & Sample designation & Tensile strength [MPa] & Tensile modulus [GPa] & Elongation @ break [\%] \\
\hline & E0 & 65 & 1.20 & 4.8 \\
\hline & E1 & 63 & 0.99 & 5.4 \\
\hline & E2 & 62 & 0.91 & 5.7 \\
\hline & E3 & 61 & 0.90 & 5.6 \\
\hline \multirow{5}{*}{$\begin{array}{l}\text { Flexural } \\
\text { properties }\end{array}$} & Sample designation & Flexural strength [MPa] & Flexural modulus [GPa] & Flexural strain to failure [\%] \\
\hline & E0 & 126 & 6.0 & 2.2 \\
\hline & E1 & 124 & 5.9 & 2.8 \\
\hline & E2 & 121 & 5.4 & 2.6 \\
\hline & E3 & 120 & 5.0 & 2.6 \\
\hline \multirow{5}{*}{$\begin{array}{l}\text { Impact } \\
\text { properties }\end{array}$} & Sample designation & \multicolumn{3}{|c|}{ Impact strength $\left[\mathrm{J} / \mathrm{m}^{2}\right]$} \\
\hline & E0 & \multicolumn{3}{|c|}{70} \\
\hline & E1 & \multicolumn{3}{|c|}{110} \\
\hline & E2 & \multicolumn{3}{|c|}{130} \\
\hline & E3 & \multicolumn{3}{|c|}{90} \\
\hline
\end{tabular}


flexural strain to failure [\%] values of the cured neat epoxy and Epoxy/MDPR blends are reported in Table 2. As expected, the addition of MDPR results in the reduction of the tensile strength, tensile modulus, flexural strength and flexural modulus. This is perhaps due to the dissolution of the epoxy resin matrix by the addition of the any liquid rubber [24, 25]. However, elongation at break and flexural strain to failure percentage values of the Epoxy/MDPR blends are higher than those of the neat epoxy resin. This shows that the rubber modified epoxy has undergone higher percentage of strain (ductile deformation) before failure, which will significantly contribute in enhancing the toughness property of the epoxy resin. This is further supported by the SEM micrographs of Epoxy/ MDPR blends, which is shown in the next section. In line with this, the impact strength values of Epoxy/MDPR blends are higher than that of the unmodified epoxy (Table 2). The impact strength of neat epoxy increases with the increase in loading

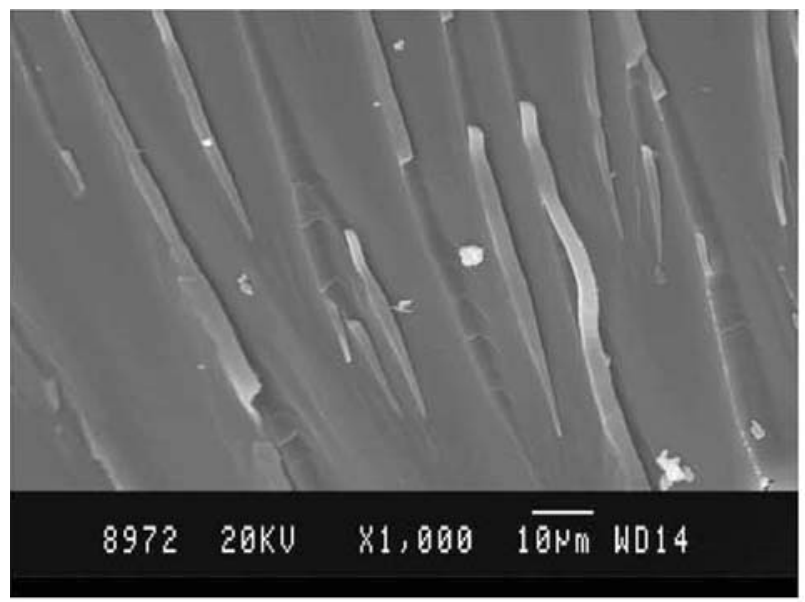

a)

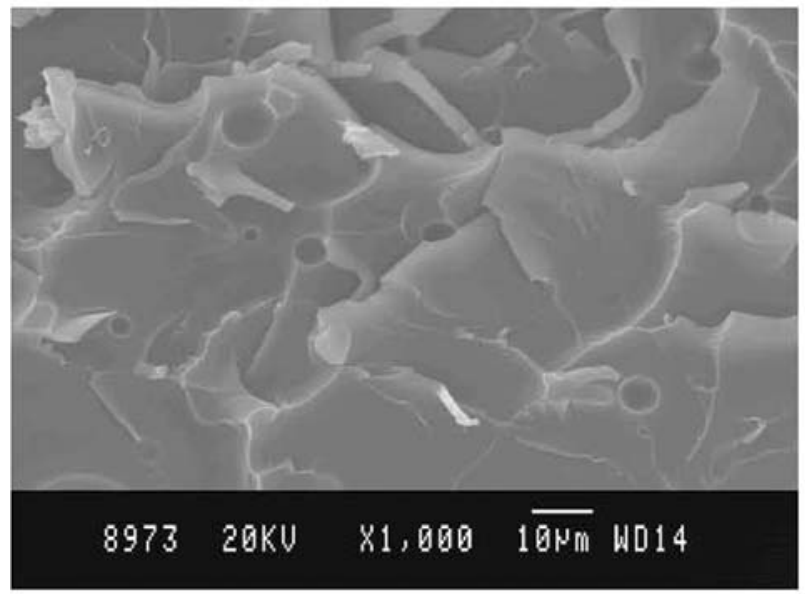

c) of MDPR up to 2 weight percentage and decreases at 3 weight percentage of MDPR concentration. The reason for this behavior has been explained in detail in the next section by considering the phase separation effect of the MDPR in the epoxy matrix.

\subsection{Fractography}

The SEM photomicrographs of the tensile fractured neat epoxy and Epoxy/MDPR blends are shown in Figure $8 \mathrm{a}-\mathrm{d}$. The SEM photo micrographs of Epoxy/MDPR blends show the distribution of globular rubber particles in the epoxy matrix. In the case of sample E1 and E2 the dispersed rubber particles have dimension in the range of 1-6 $\mu \mathrm{m}$ and the rubber particles are uniformly distributed throughout the epoxy matrix. However, in the case of sample E3 the size of the dispersed rubbery domains are much larger and the rubbery particles are not uniformly distributed throughout the epoxy matrix. In the micrographs of samples E1 and E2,

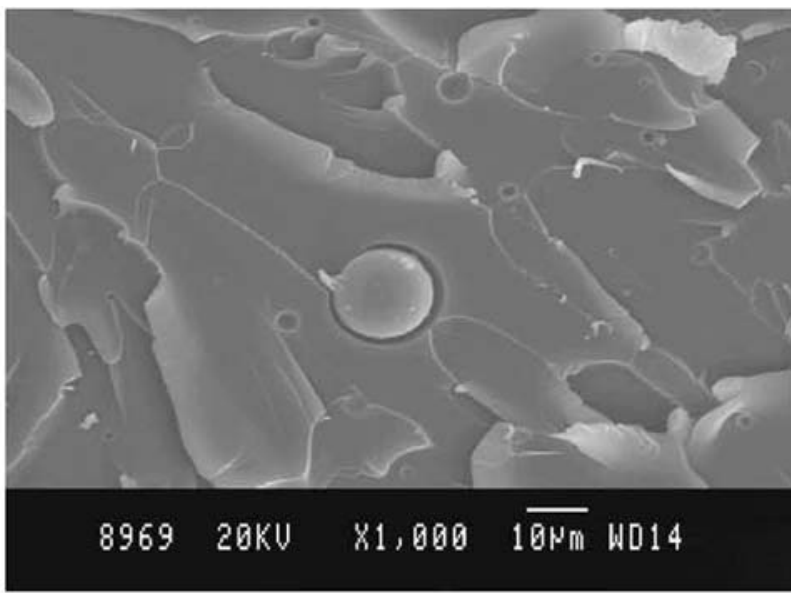

b)

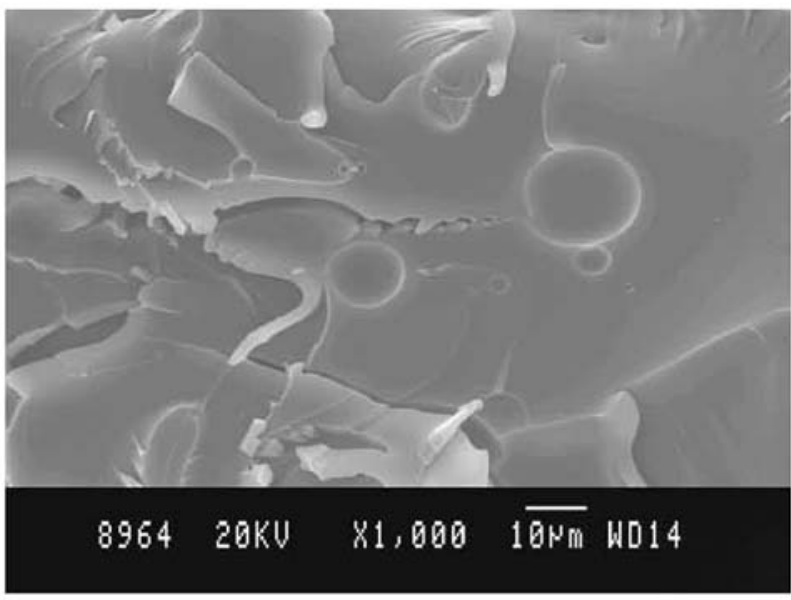

d)

Figure 8. SEM micrograph of fractured surface of sample E0 (a), SEM micrograph of fractured surface of sample E1 (b), SEM micrograph of fractured surface of sample E2 (c), SEM micrograph of fractured surface of sample E3 (d) 
one can see shear banding between the rubber particles, which suggest appreciable matrix shear yielding and plastic deformation over a large volume. This is the primary cause for energy absorption mechanism in the case of rubber-toughened epoxy [24-27]. However, this effect is more prominently seen in the case of sample E2. Hence for sample E2, both toughening and flexibilisation effects (mild dilution effect of the epoxy matrix) can be operative, resulting in maximum improvement in impact strength. In the case of neat epoxy resin, there is no evidence of any ductile fracture process (matrix shear yielding) which further substantiates the brittle nature of the fracture process. The poor fracture property of sample E3 can also be explained by considering the morphology as observed in the SEM. The SEM photograph indicates the presence of large particles distributed haphazardly. The larger particles cannot act efficient in dissipating mechanical energy but instead act as defects $[25,26]$.

\subsection{Positron annihilation lifetime studies (PALS)}

The data from PALS gives the following information of interest for studies of this type - values of free volume hole size, $V_{f}$ in $\mathrm{nm}^{3}, I_{3}$ in $\%$ which is a measure of the number density of the free volume holes. The product of these two parameters is $F_{v}$, which gives the overall fractional free volume. The values of these parameters for the samples E0, E1, E2 and E3 are reported in Table 1. Elongation at break and toughness depend on free volume parameters. They depend on the ease with which the polymer chains can slide past each other under load. Thus increase in $V_{f}$ values can be expected to provide more space for the chain movements-thus elongation at break increases with modifier content upto $2 \mathrm{phr}$ levels. Since the level of addition of the modifier is very low, the changes in these properties are not dramatic. The $V_{f}$ and $F_{v}$ values show the same trend with the level of modifier addition. However, the effect of modifier addition on, $I_{3}$ values show a different trend - a slight decrease in these values with modifier addition upto $2 \mathrm{phr}$ addition - this may be due to cross linking of the resin by the modifier - as each anhydride group can react with two epoxy rings. The probability of this reaction is good at high temperature cure as is the case here - at higher temperatures, the resin has lower viscosity and this can help in the anhydride group in the modifier to react with new epoxy rings in other chains leading to cross linking. At $3 \mathrm{phr}$ level the $I_{3}$ value increases - this may be due to the additive effect of the modifier (here a rubbery oligomer) which should have more free volumes compared with the epoxy resin. The glass transition temperature $\left(T_{g}\right)$ values also reflect the trend shown by the free volume parameters.

\section{Conclusions}

Maleated depolymerised natural rubber (MDPR) has been developed by grafting maleic anhydride with depolymerised natural rubber. The FT-IR spectrum and ${ }^{1} \mathrm{H}-\mathrm{NMR}$ spectroscopy of the MDPR confirms the grafting and explains the reaction mechanism between maleic anhydride and depolymerised natural rubber. The FT-IR spectra of the uncured Epoxy/MDPR blends confirm the reactions between the acid/anhydride moiety of MDPR and the epoxy group of the epoxy resin. The addition of MDPR to epoxy resin does not significantly alter the glass transition temperature $\left(T_{g}\right)$ value of the neat epoxy resin. This is attributed to the limited compatibility between MDPR and epoxy resin. The addition of MDPR to epoxy resin results in an increase in the elongation at break and flexural strain to failure values with some expense in other mechanical properties. The unnotched Izod impact strength values of the 99/1 (E1) and 98/2 (E2) Epoxy/MDPR blends are higher than impact strength value of the unmodified epoxy (E0). However, the impact strength value of $97 / 3$ (E3) blend is lower than the impact strength values of 99/1 (E1) and 98/2 (E2) blends. The SEM micrographs of 99/1 (E1) and 98/2 (E2) blends show shear banding between the uniformly phase separated rubber particles, which advocate appreciable matrix shear yielding and plastic deformation over a large volume. This is attributed to the improvement of the impact strength values of the 99/1 (E1) and 98/2 (E2) Epoxy/MDPR blends. However, in the case of 97/3 (E3) blend, though there is phase separation, the rubber particles are phase separated randomly with irregular particle size. This may explain the poor performance of the $97 / 3$ (E3) blend system. PALS show the usual increase in free volume parameters with the addition of the rubbery modi- 
fier but the number density of the free volume holes show a decrease upto $2 \mathrm{phr}$ level addition of the modifier - this may be due to some cross linking between the resin chains by the maleic anhydride group present in the modifier. These trends are reflected by the glass transition $\left(T_{g}\right)$ values measured by differential scanning calorimetry.

\section{Acknowledgements}

The authors acknowledge M/S.Carborundum Universal India Private Limited for providing Depolymerised Natural Rubber.

\section{References}

[1] Potter W. G.: Epoxide resins. Springer-Verlag, New York (1970).

[2] May C. A.: Epoxy resins: Chemistry and technology. Marcell Dekker, New York (1973).

[3] Bouer R. S.: Epoxy resin chemistry. American Chemical Society, Washington (1979).

[4] Bascom W. D., Hunston D. L.: Rubber toughened plastics. American Chemical Society, Washington (1989).

[5] McGarry F. J., Rosner R. B.: Epoxy-rubber interactions. in 'Toughened plastics I. Science and Engineering' (eds.: Riew C. K., Kinloch A. J.) Advances in Chemistry Series, Washington, 305-315 (1993).

[6] Sultan J. N., McGarry F. J.: Effect of rubber particle size on deformation mechanisms in glassy epoxy. Polymer Engineering and Science, 13, 29-34 (1973).

[7] Manzione L. T., Gillham J. K., McPherson C. A.: Rubber-modified epoxies, I. Transitions and morphology. Journal of Applied Polymer Science, 26, 889905 (1981).

[8] Manzione L. T., Gillham J. K.: Rubber-modified epoxies, II. Morphology and mechanical properties. Journal of Applied Polymer Science, 26, 907-919 (1981).

[9] Riew C. K.: Amine terminated reactive liquid polymers: Modification of thermoset resins. Rubber Chemistry and Technology, 54, 374-402 (1981).

[10] Pocius A.: Elastomer modification of structural adhesives. Rubber Chemistry and Technology, 58, 622636 (1985).

[11] Reizaifard A. H., Hodd K. A., Tod D. A., Barton J. M.: Toughening epoxy resins with poly (methyl methacrylate)-grafted-natural rubber, and its use in adhesive formulations. International Journal of Adhesion and Adhesives, 14, 153-159 (1994).
[12] Kemp T. J., Wiford A., Howarth O. W., Lee T. C. P.: Structural and materials properties of a polysulphidemodified epoxide resin. Polymer, 33, 1860-1871 (1992).

[13] Tong J., Bai R., Pan C., Goethals E. J.: Flexibility improvement of epoxy resin by using polysiloxanePGMA (MMA) composite particles. Journal of Applied Polymer Science, 57, 895-901 (1995).

[14] Ratna D., Banthia A. K.: Rubber toughened epoxy. Macromolecular Research, 12, 11-21 (2004).

[15] Suzuki T., Oki Y., Numajiri M., Miura T., Kondo K., Ito Y.: Positron annihilation and polymerization of epoxy resins. Polymer, 34, 1361-1365 (1993).

[16] Mogensen O. E., Jacobsen F., Pethrick R. A.: Positron annihilation in a rubber modified epoxy resin. Polymer, 20, 1034-1036 (1979).

[17] Goyanes S., Rubiolo G., Salgueiro W., Somoza A.: On the free volume evolution in a deformed epoxy composite. A positron annihilation study. Polymer, 46, 9081-9087 (2005).

[18] Goyanes S., Rubiolo G., Marzocca A., Salgueiro W., Consolati G., Somoza A., Mondragon I.: Yield and internal stresses in aluminum filled epoxy resin. A compression test and positron annihilation analysis. Polymer, 44, 3193-3199 (2003).

[19] Derouet D., Phinyocheep P., Boccaccio G., Brosse J. C.: Synthesis of photo-crosslinkable elastomers by chemical modification of liquid natural rubber. Journal of Natural Rubber Research, 6, 39-54 (1991).

[20] Naunton W. J. S.: Applied science of rubber. Edward Arnold Publishing, London (1961).

[21] Roberts A. D.: Natural rubber science and technology. Oxford University Press, Oxford (1988).

[22] Brydson J. A.: Rubber chemistry. Applied Science Publishers, London (1978).

[23] Kothandaraman B., Kulshreshtha A. K.: Rubber modified thermosets. in 'Handbook of polymer blends and composites' (eds.: Vasile C., Kulshreshtha A. K.) Rapra Technology, Shrewsbury, Vol 4, 417-440 (2003).

[24] Bucknall C. B.: Toughened plastics. Applied Science Publishers, London (1977).

[25] Kinloch A. J.: Relationship between the microstructure and fracture behavior of rubber-toughened thermosetting polymer. in 'Rubber toughened plastics' (ed.: Riew C. K.) Advances in Chemistry Series, Washington, 67-91 (1989).

[26] Levita G.: Matrix ductility and toughening of epoxy resins. in 'Rubber toughened plastics' (ed.: Riew C. K.) Advances in Chemistry Series, Washington, 93-118 (1989).

[27] Banthia A. K., Chaturvedi P. N., Jha V., Pendyala V. N. S.: Synthesis, characterization and evaluation of telechelic acrylate oligomers and related toughened epoxy networks. in 'Rubber toughened plastics' (ed.: Riew C. K.) Advances in Chemistry Series, Washington, 343-359 (1989). 